\title{
No persistent behavioural effects of SCUBA diving on reef sharks
}

\author{
Darcy Bradley ${ }^{1, *}$, Yannis P. Papastamatiou ${ }^{2}$, Jennifer E. Caselle ${ }^{3}$ \\ ${ }^{1}$ Bren School of Environmental Science and Management, University of California Santa Barbara, Santa Barbara, CA 93106, USA \\ ${ }^{2}$ Department of Biological Sciences, Florida International University, North Miami, FL 33181, USA \\ ${ }^{3}$ Marine Science Institute, University of California Santa Barbara, Santa Barbara, CA 93106, USA
}

\begin{abstract}
Despite rapid growth in the marine tourism sector, the impacts of recreation on the marine environment are generally not well understood. Most existing studies of marine recreation ecology have focused on behavioural changes resulting from direct interactions between humans and wildlife including provisioning. However, non-consumptive, non-provisioning human impacts may also result in persistent behavioural impacts to shark populations. In this study, we examined differences in residency, abundance, and behaviour of reef sharks at Palmyra Atoll in response to long-term SCUBA diving activity, using a combination of survey techniques including baited remote underwater video systems and multi-year passive acoustic monitoring. In most locations with recreational diving operations, some level of human impact is pervasive, but on Palmyra, extractive fishing is prohibited, and scientific diving activities are concentrated on just a few sites that house long-term monitoring projects. These sites experience relatively intensive diving, while the majority of the island is entirely undived. Evidence from elsewhere has shown that sharks behaviourally respond to people in the water over short time scales, but our results indicate that this response may not persist. We did not detect differences in reef shark abundance or behaviour between heavily dived and undived locations, nor were there differences in shark residency patterns at dived and undived sites in a year with substantial diving activity and a year without any diving. Our results suggest that humans can interact with reef sharks without persistent behavioural impacts, and that well-regulated shark diving tourism can be accomplished without undermining conservation goals.
\end{abstract}

KEY WORDS: Shark $\cdot$ Tourism $\cdot$ Predator $\cdot$ Residency $\cdot$ Abundance $\cdot$ Behavioural activity

\section{INTRODUCTION}

To combat pervasive overexploitation of sharks (Baum \& Myers 2004, Robbins et al. 2006, Ferretti et al. 2008, Ward-Paige et al. 2010b, Davidson et al. 2015), several countries have taken legislative action to ban the harvest and sale of sharks and shark products (Daves \& Nammack 1998, Cortés \& Neer 2006, Sybersma 2015), and some have encouraged sharkwatching tourism as a sustainable alternative to shark fishing (Topelko \& Dearden 2005, Dobson 2006). Shark tourism has contributed millions of dollars annually to many economies (reviewed in Topelko

\footnotetext{
*Corresponding author: darcybradley@ucsb.edu
}

\& Dearden 2005, Gallagher \& Hammerschlag 2011), and shark diving can generate higher economic returns than shark fishing (Anderson \& Ahmed 1993, Gallagher \& Hammerschlag 2011, Vianna et al. 2012, Cisneros-Montemayor et al. 2013). Many shark species are relatively long-lived, so even with a high discount rate, revenue from a live animal can accrue over many years.

Although studies have lauded non-consumptive tourism and recreation for its positive benefits to ocean ecosystems (Biggs et al. 2012, Halpern et al. 2012), there is also a negative side to ecotourism that can degrade habitats, disrupt ecosystems, and alter

(1) The authors 2017. Open Access under Creative Commons by Attribution Licence. Use, distribution and reproduction are unrestricted. Authors and original publication must be credited. 
animal behaviour, even reducing fitness in some cases (reviewed in Boyle \& Samson 1985, Boo 1991, Krüger 2005). Tourism activities on land have been associated with reduced breeding success (Ellenberg et al. 2006), decreased foraging and feeding rates (Müllner et al. 2004, Yasué 2005), and lowered juvenile survival rates (Müllner et al. 2004) in several bird species. Similarly, human disturbance has altered activity budgets and led to increased vigilance and decreased foraging in elk (Naylor et al. 2009, Ciuti et al. 2012).

While the field of recreation ecology is well developed in the terrestrial literature (reviewed in Leung \& Marion 2000, Steven et al. 2011), impacts of recreation on the marine environment are not well understood despite rapid growth in the marine tourism sector. However, there is a growing interest in documenting non-consumptive human impacts on marine systems (reviewed in Madin et al. 2016). For example, there is evidence that human recreational activities can disrupt activity budgets of seals and orcas (Kovacs \& Innes 1990, Williams et al. 2006, Stafford-Bell et al. 2012), reduce social interactions in southern right whales (Vermeulen et al. 2012), and cause acute behavioural changes and chronic spatial displacement in bottlenose dolphins (Scarpaci et al. 2000, Constantine \& Zealand 2001, Constantine et al. 2004, Lusseau 2004). Following intense tourism activity and provisioning, the naturally solitary southern stingray developed shoaling behaviour, changed feeding habits, and experienced a higher rate of injury and larger parasite load resulting in an overall lower body condition than stingrays at non-tourist sites (Shackley 1998, Semeniuk \& Rothley 2008). Hawksbill turtles may also decrease time spent eating and breathing in response to an approaching SCUBA diver (Hayes et al. 2016), and reef fish may forgo cleaning opportunities in the presence of divers (Titus et al. 2015).

Despite significant resources aimed towards establishing shark sanctuaries and promoting shark diving tourism, the impact of recreational SCUBA diving on shark species is largely unknown (Vianna et al. 2012). This question is pressing, because disturbing predator populations can induce cascading changes to marine communities (Heithaus et al. 2008, Babcock et al. 2010), and indirect behavioural effects resulting from human impacts are likely to disrupt marine ecosystems (Madin et al. 2016). To date, the shark tourism literature has largely focused on provisioning, or shark feeding, and how it may result in behavioural changes that alter the ecological function of these top predators. For example, over rela- tively short time scales, provisioning caused changes in daily vertical space use, activity budgets, and metabolic rate of whitetip reef sharks Triaenodon obesus (Fitzpatrick et al. 2011, Barnett et al. 2016), increased residency in sicklefin lemon sharks Negaprion acutidens (Clua et al. 2010), and increased local abundance in bull sharks Carcharhinus leucas (Brunnschweiler \& Baensch 2011). Over longer time scales, provisioning had no effect on residency and space use in Caribbean reef sharks Carcharhinus perezii (Maljkovi \& Côté 2011) and tiger sharks Galeocerdo cuvier (Hammerschlag et al. 2012), and had only minimal behavioural effects that decreased with time in white sharks Carcharodon carcharias (Laroche et al. 2007), but resulted in significant changes to the relative abundance of several shark species at a multi-species shark feeding site in Fiji (Brunnschweiler et al. 2014) and to shark communities in Hawaii (Meyer et al. 2009). There is some evidence that SCUBA diving activity, absent provisioning, can also lead to short-term changes in shark behaviour, with sharks both evading and approaching groups of recreational divers (Quiros 2007, Cubero-Pardo et al. 2011) and changing activity budgets while in the presence of SCUBA divers (Smith et al. 2010, Baronio 2012). SCUBA divers also caused the spatial displacement of grey nurse sharks Carcharias taurus over short time scales (Baronio 2012). However, these studies exclusively measured the immediate behavioural responses of sharks to divers in the water, and did not consider the potential cumulative effects of diving activity over longer time scales.

A major concern to emerge from these findings, which is virtually untested in marine systems, is that non-consumptive, non-provisioning human impacts may also result in chronic spatial displacement-as has been observed in large terrestrial and marine mammals that shifted space use away from human activities (Constantine \& Zealand 2001, George \& Crooks 2006). If sharks permanently shift their space use away from reefs frequented by recreational divers over long time scales, then human presence could undermine spatial protection strategies, such as marine refuges and shark sanctuaries, by forcing sharks out of protected areas and into zones open to fishing.

In this study, we set out to resolve this concern by assessing chronic differences in the space use, abundance, and behaviour of reef sharks at heavily dived and undived sites at Palmyra Atoll using a combination of survey techniques including baited remote underwater video systems and multi-year passive 
acoustic monitoring. Palmyra is a remote, historically uninhabited, US National Wildlife Refuge in the central Pacific Ocean that supports a large population of blacktip reef Carcharhinus melanopterus and grey reef sharks Carcharhinus amblyrhynchos. In most locations with recreational diving operations, some level of human impact is pervasive, but on Palmyra, scientific diving activities are concentrated on just a few sites that house long-term monitoring projects. These sites experience relatively intensive research diving, particularly during May to August, while the majority of the island is entirely undived. This longterm concentration of SCUBA diving activity in just a few dive sites around Palmyra provides a stark and persistent difference in disturbance regime with which to test hypotheses about long-term diving impacts. In addition, in 2015, logistical constraints caused there to be no research diving activity in Palmyra prior to our study in September; the atoll had therefore been undived for an entire year, providing an opportunity to examine the time scales of human presence effects on the abundance, behaviour, and spatial distribution of reef sharks due to this relatively short-term refuge from historically intense diving activity. We then assessed multi-year residency patterns of reef sharks at dived and undived sites to compare shark residency in contrasting years - one with substantial SCUBA diving activities (2014), the other without diving (2015). We hypothesized that persistent SCUBA diving would change the space use and residency of mobile reef sharks; if sharks avoid locations with chronic diving activity, then relative abundance and residency will be lower, and if sharks are attracted to locations with persistent diving activity, then relative abundance and residency will be higher.

\section{MATERIALS AND METHODS}

\author{
Study site
}

Palmyra Atoll is located in the central Pacific $\left(5^{\circ} 54^{\prime} \mathrm{N}, 162^{\circ} 05^{\prime} \mathrm{W}\right)$ and was established as a US Fish and Wildlife Refuge in 2001. The Marine Refuge and Marine National Monument extend out 50 nautical miles, and are managed by The Nature Conservancy (TNC) and the US Fish and Wildlife Service. Commercial fishing and extractive recreational fishing are banned within the refuge.

\section{Baited remote underwater video systems (BRUVs)}

BRUVs have become the standard tool for monitoring large-bodied, potentially cautious reef fish including sharks (Meekan \& Cappo 2004, Malcolm et al. 2007). BRUVs are non-invasive, repeatable, and allow the collection of data on the relative abundance and distribution of the marine faunal community (Harvey et al. 1996, 2001), particularly for motile fauna. The use of bait with the BRUV system serves to attract motile predators to the camera unit; while bait increases the abundance of generalist carnivores in the area immediately surrounding the BRUV system, fish behaviour (e.g. shyness, boldness, inter and intraspecific interactions) likely play a role in determining the assemblage observed (Whitmarsh et al. 2016)

During August and September 2015, we conducted 50 BRUV surveys on Palmyra's forereef habitat at 4 research (dived, $\mathrm{n}=25$ surveys) and 4 non-research (undived, $\mathrm{n}=25$ surveys) sites (Fig. 1). The research sites (Penguin Spit, FR5, FR7, and FR9) that were sur-

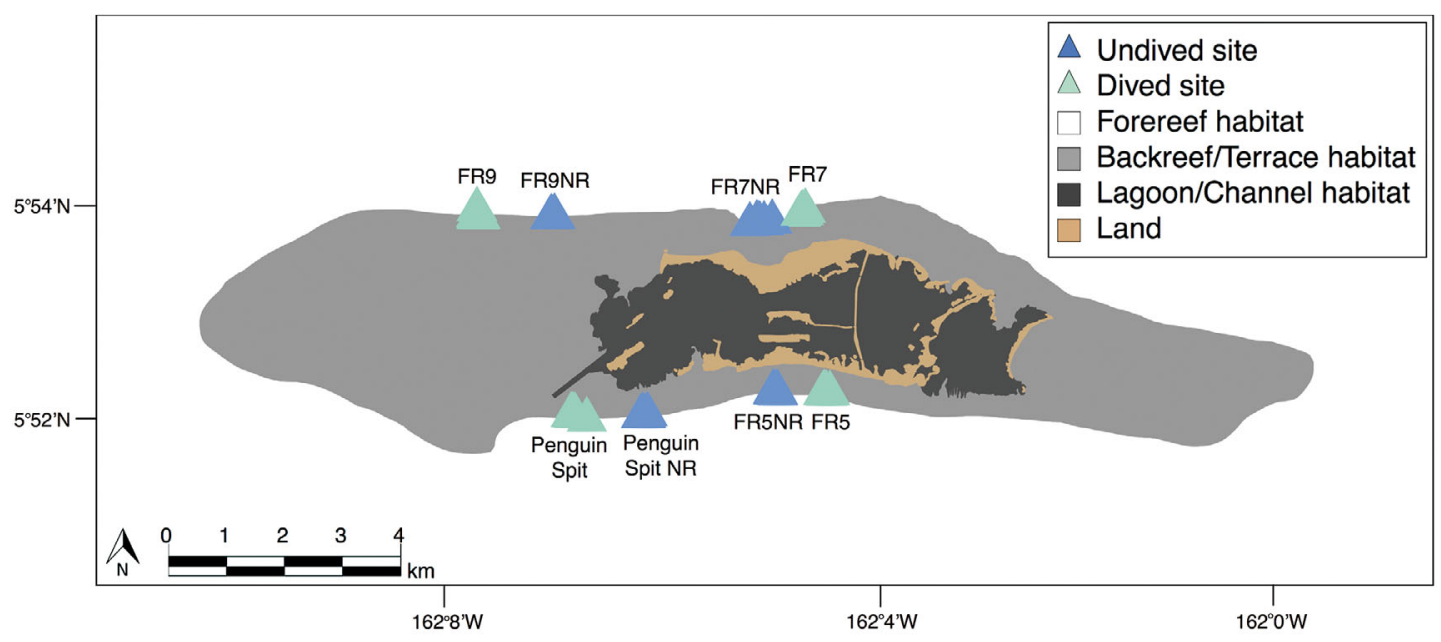

Fig. 1. Location of baited remote underwater video (BRUV) surveys on Palmyra's forereef habitat at dived $(\mathrm{n}=25)$ and undived $(n=25)$ sites 
veyed were the most dived sites on Palmyra's forereefs (Fig. 1). Research sites were originally selected based on accessibility and coverage of both north and south forereefs; site selection was not based on habitat features or presence of particular species, but site usage was maintained to (1) minimize disturbance within the marine refuge, and (2) maximize information collection via data sharing and long-term monitoring. Between 2012 and 2014, there was an average of 1392 dives $\mathrm{yr}^{-1}$ completed by groups of divers at Palmyra, with particularly high diving pressure during the summer 'research' season (May to August; TNC diving safety officer [DSO] Z. Caldwell pers. comm.). Research sites included in this study (herein referred to as 'dived' sites) are where the majority of Palmyra's SCUBA diving occurs; research diving activities primarily include deploying and removing research equipment (e.g. instruments, settlement plates, markers, cages, moorings) and conducting underwater visual surveys (UVS). Sites herein referred to as 'undived' have been visited 1 to 3 times over the last 15 yr by NOAA's Coral Reef Ecosystem Program divers, or are dived once annually for $\sim 15$ min by a pair of divers to collect and redeploy an acoustic receiver (FR5NR, FR7NR).

BRUVs were deployed for $120 \mathrm{~min}$ in depths between 8 and $30 \mathrm{~m}$. Individual sites were surveyed 6 to 7 times at slightly different locations (within $100 \mathrm{~m}$ of each other) and at various depths with a minimum of $24 \mathrm{~h}$ between repeat sampling (Fig. 1). All BRUVs were deployed during daylight hours (08:00 to 17:00 h), and each location was sampled at multiple times of the day to prevent bias with respect to diel influences on fish assemblages (Birt et al. 2012). We used GoPro Hero cameras (4 Silver), mounted on PVC or metal frames (BRUV systems), which we lowered to the reef floor from the boat using a surface line (in areas without live coral) or were diver-deployed (in areas with high coral cover, as required by our US National Wildlife Refuge permit) by swimming the system to the reef and attaching it to non-living substrate using lashing straps. All BRUVs were baited with standardized amounts of mackerel $(0.5 \mathrm{~kg})$, cut into $\sim 10 \mathrm{~cm}$ sections, which appeared in the video frame. Bait was concealed within a plastic canister that contained small holes to allow a bait plume to form while ensuring that animals could not obtain a reward by actively feeding on bait. Our BRUV setup therefore did not mimic recreational provisioning effects. BRUV surveys were conducted simultaneously (within 30 min of each other) in a paired design so that one system was at a dived site and one was in an adjacent, undived site. To precisely assess the distance travelled by a bait plume, Cappo et al. (2004) developed an equation that considers current speeds and tidal movements; however, currents on Palmyra's forereefs are highly variable and unpredictable and we were unable to use this equation to inform our study design. Previous studies have demonstrated that distances of $100 \mathrm{~m}$ (Ellis \& Demartini 1995) and $450 \mathrm{~m}$ (Cappo et al. 2004) between simultaneously deployed BRUV systems were adequate to ensure independence. Evidence from Palmyra also suggests that sharks limit movement within small core areas during the day (largely remaining around single acoustic receivers with a $300 \mathrm{~m}$ range), with larger-scale movements made primarily at night (Y. P. Papastamatiou unpubl. data). Therefore, we used a minimum distance of $1 \mathrm{~km}$ between dived and undived sites (Fig. 1) to minimize connectivity during concurrent surveys, and selected undived sites based on similarities in their biotic and abiotic characteristics to adjacent dived sites (e.g. habitat, species composition, topography, exposure, currents).

All video footage was analysed using the SeaGIS software EventMeasure (version 4.4). We analysed the first 90 min of video following deployment where start time was the moment the BRUV landed on the bottom for lowered systems, and the time at which the diver was no longer visible in the video frame for diver-deployed BRUVs. For each BRUV survey, we recorded maximum number of individuals in-frame $(\operatorname{MaxN})$, time of $\operatorname{MaxN}$, and time of first sighting $\left(T_{\text {arrive }}\right)$ for every species of predator (for a full species list see Table S1 in the Supplement at www.int-res. com/articles/suppl/m567p173_supp.pdf). MaxN is commonly used as a metric of relative abundance; in order to avoid double-counting individuals, MaxN counts only the maximum number of fish recorded in a single video frame. MaxN positively correlates with fish abundance and $T_{\text {arrive, }}$ because fish are more likely to arrive at the bait quickly if their abundance is high (Ellis \& Demartini 1995, Willis \& Babcock 2000). Estimates of MaxN are considered a conservative representation of fish abundance, particularly when fish density is high (Cappo et al. 2004, 2007). For each shark species, we visually examined patterns in MaxN and $T_{\text {arrive }}$ at paired dived and undived sites (Fig. S1 in the Supplement). Given limited sample sizes at individual sites $(n=6$ or 7$)$, dived and undived sites were pooled and $t$-tests were used to examine differences in MaxN, time of MaxN, and $T_{\text {arrive. }}$. If SCUBA diving activity spatially displaced reef sharks, we predicted that MaxN would be higher at undived than dived sites, and time of MaxN and $T_{\text {arrive }}$ would be earlier at undived than dived sites. 
To ensure that there were no significant differences in the structure of faunal assemblages between sites - and that sites were directly comparable — we constructed a similarity matrix using the Bray-Curtis similarity coefficient. A non-metric multidimensional scale (nMDS) ordination plot of relative abundance estimates (i.e. MaxN) was examined to identify patterns in predatory fish assemblages between surveyed sites, and an ordered 1-way analysis of similarities (ANOSIM) was used to test for differences in assemblage structure between sites. One-way ANOVAs and Tukey HSD post hoc tests were used to compare predator richness across sites, and a $t$-test was used to assess differences in species richness at dived and undived sites. We also assessed differences in MaxN, time of MaxN, and $T_{\text {arrive }}$ between deployment methods and over the course of the study for each reef shark species to ensure that no bias was introduced via method of deployment or repeated sampling.

\section{Acoustic monitoring}

Between 2010 and 2012, acoustic transmitters (69 kHz, V16; Vemco) with an estimated battery life of $3.4 \mathrm{yr}$ were surgically implanted in 45 grey reef sharks on Palmyra's forereefs (for surgery details see Papastamatiou et al. 2009). Shark movement was passively tracked using stationary acoustic receivers (VR2; Vemco). Part of Palmyra's large acoustic array includes receivers at 4 of the sites surveyed by BRUVs: FR9 (dived), Penguin Spit (dived), FR5NR (undived), FR7NR (undived) (Fig. 1). Detection radii for VR2 receivers at Palmyra is approximately $300 \mathrm{~m}$ (Papastamatiou 2008). Data from each VR2 were downloaded annually.

To test the hypothesis that SCUBA diving activity spatially affects reef sharks, we examined patterns of site residency and presence during a year with SCUBA divers present (2014) and one without diving (2015). From May to August 2014, 789 SCUBA dives were completed on Palmyra's forereefs, most of which were at the 4 dived sites include in this study, whereas no dives were conducted during May to August 2015 (TNC DSO pers. comm.). We assessed shark residency patterns by determining the number of days each shark was detected on dived and undived sites from January to August in 2014 and 2015. Only sharks detected anywhere on the receiver array throughout the year were included in the analysis. For each month and year, we calculated a site residency index for each shark at FR9, Penguin Spit,
FR5NR, and FR7NR (Fig. 1). A shark was considered present at a receiver if it was detected more than once in the same day (Carlson et al. 2008). The site residency index was then defined as the number of days each individual was present at a receiver in a given month divided by the number of days in that month. Residency indices are reported as proportions (with a range between 0 to 1 ), with values closer to 1 indicating a higher degree of site residency. We were interested in whether residency patterns differed between dived and undived sites in a year with diving (2014), and whether residency patterns during periods with high diving intensity (May to August 2014) were significantly different from residency patterns during a year without diving (2015).

Mixed effect models were used to assess the effects of seasonal (month) and human use (dived and undived sites and years) drivers on residency patterns of grey reef sharks. Site and individual were included as random effects in the model, and a logit link and the binomial distribution were used, because the response variable, residency, is reported as a proportion. Models were constructed using the 'glmer' function in the 'Ime4' package in R (Bates et al. 2015), and Akaike's information criterion (AIC) was used to assess model performance against a null model (random effects only).

\section{RESULTS \\ BRUVs}

In total, 30 unique species of predatory fishes were recorded from 6 distinct families: sharks (Carcharhinidae), trevallies (Carangidae), snappers (Lutjanidae), groupers (Serranidae), emperors (Lethrinidae), and eels (Muraenidae) (Fig. 2). At least 1 species of reef shark was observed in every survey, and all 3 species of reef shark (blacktip, grey reef, and whitetip) were present in 8 of the 50 surveys (6 dived, 2 undived). Blacktip reef sharks were observed in the most surveys, followed by grey reef sharks, and then whitetip reef sharks $(98,62$, and $22 \%$, respectively). Given the relative rarity of whitetip reef sharks, differences in MaxN, time of MaxN, and $T_{\text {arrive }}$ at dived and undived sites were only examined for blacktip and grey reef sharks.

No significant differences were found in MaxN, time of MaxN, or $T_{\text {arrive }}$ between dived and undived sites for blacktip or grey reef sharks (Table 1, Fig. 3). Blacktip reef sharks had higher MaxN and earlier $T_{\text {arrive }}$ and time of MaxN than grey reef sharks across 


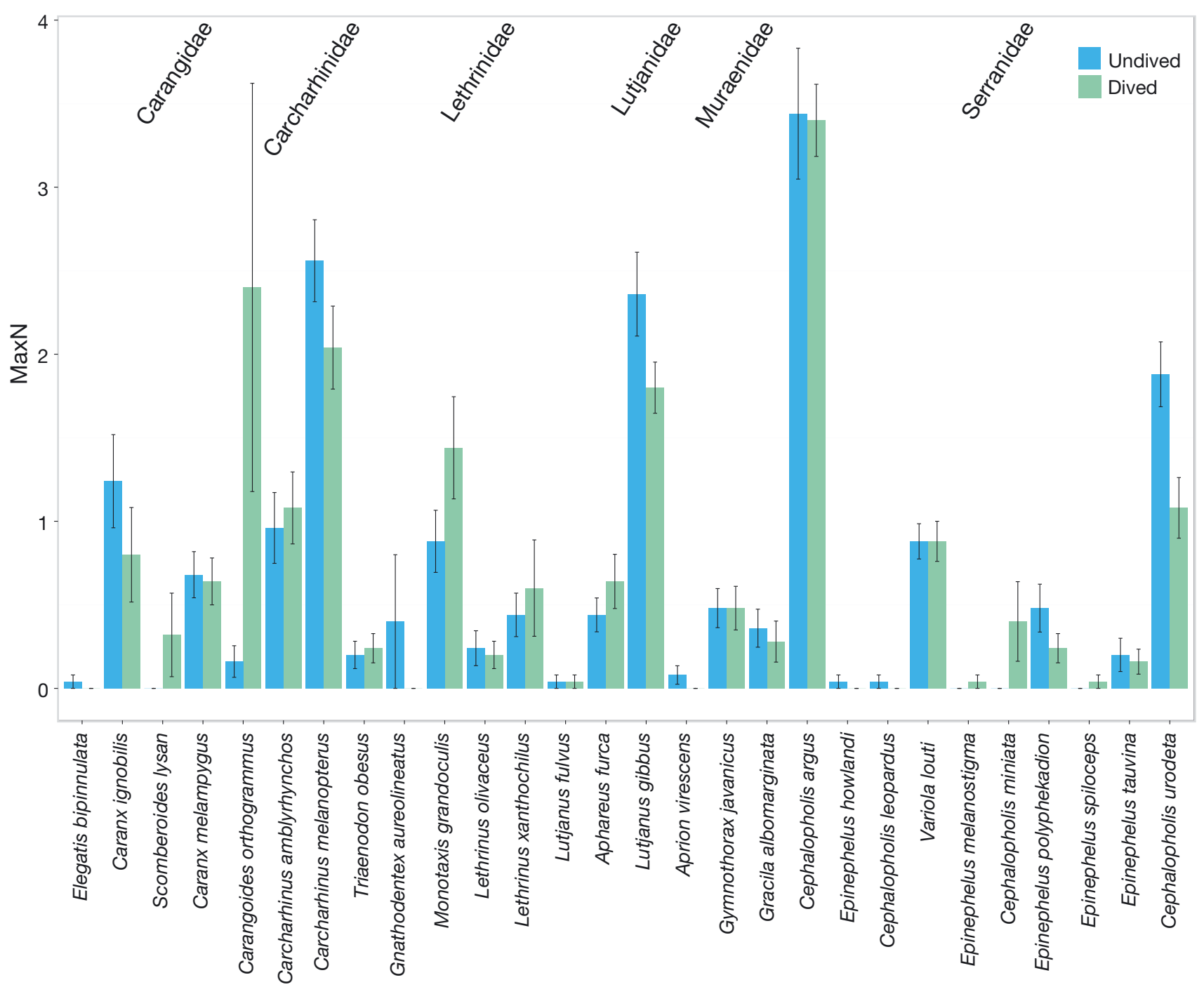

Fig. 2. Average ( $\pm 1 \mathrm{SE}$ ) relative abundance (MaxN) of all predators at Palmyra Atoll in dived (green) and undived (blue) sites. Note: Lutjanus bohar is not shown because MaxN was significantly higher than for all other species $(9.5$ and 7.5 , dived and undived, respectively)

dived and undived locations. We were able to rule out sources of bias from camera deployment methods (lowered from boat vs. diver-deployed), repeated samples, and influences of depth: no differences were found in MaxN, time of MaxN, or $T_{\text {arrive }}$ as a function of camera deployment method, as a function of time for any of the species of reef shark examined, or as a function of depth (Figs. S2-S4 in the Supplement at www.int-res.com/articles/suppl/m567p173_ supp.pdf).

The maximum number of predatory species observed in a single 90 min survey was 15 (FR7NR) and minimum species richness was 6 (FR9NR). Only 1 site (FR5) had significantly lower species richness than all other sites ( $<<0.001$; Fig. S5 in the Supplement).
However, no differences were found in predator species richness $(t[47.7]=-0.80, p=0.43)$ or faunal community assemblage between dived and undived sites (ANOSIM, R = -0.07, $\mathrm{p}=0.66$ ) (Fig. 4).

\section{Acoustic monitoring}

Of the 45 acoustically tagged grey reef sharks, 36 individuals were detected on the acoustic receivers located at Penguin Spit, FR9, FR5NR, and/or FR7NR in 2014, and 16 individuals were detected in 2015. Sharks acoustically tagged in 2011 were only detected on the Palmyra array for the first few months of 2015 (likely due to expired battery life), and so 
Table 1. Relative abundance $(\mathrm{MaxN})$, time of $\mathrm{MaxN}$, or arrival time ( $\left.T_{\text {arrive }}\right)$, mean $\pm \mathrm{SE}$, from baited remote underwater video (BRUV) surveys for grey reef sharks Carcharhinus amblyrhynchos and blacktip reef sharks C. melanopterus at dived and undived sites at Palmyra Atoll. Student's $t$-test results are reported with corresponding p-values

\begin{tabular}{|lccc|}
\hline Species & MaxN & Time MaxN $(\min )$ & $T_{\text {arrive }}(\min )$ \\
\hline C. amblyrhynchos & $t(48.0)=-0.40, \mathrm{p}=0.69$ & $t(48.8)=-0.44, \mathrm{p}=0.66$ & $t(28.8)=1.37, \mathrm{p}=0.18$ \\
Dived & $1.08 \pm 0.22$ & $32.3 \pm 4.5$ & $14.2 \pm 4.5$ \\
Undived & $0.96 \pm 0.21$ & $29.2 \pm 5.3$ & $23.1 \pm 4.7$ \\
C. melanopterus & $t(48.0)=1.49 ; \mathrm{p}=0.14$ & $t(47.3)=-0.69 ; \mathrm{p}=0.50$ & $t(47.0)=-0.48 ; \mathrm{p}=0.63$ \\
Dived & $2.04 \pm 0.25$ & $38.8 \pm 5.0$ & $13.4 \pm 2.8$ \\
Undived & $2.56 \pm 0.25$ & $34.2 \pm 4.4$ & $11.4 \pm 2.9$ \\
\hline
\end{tabular}
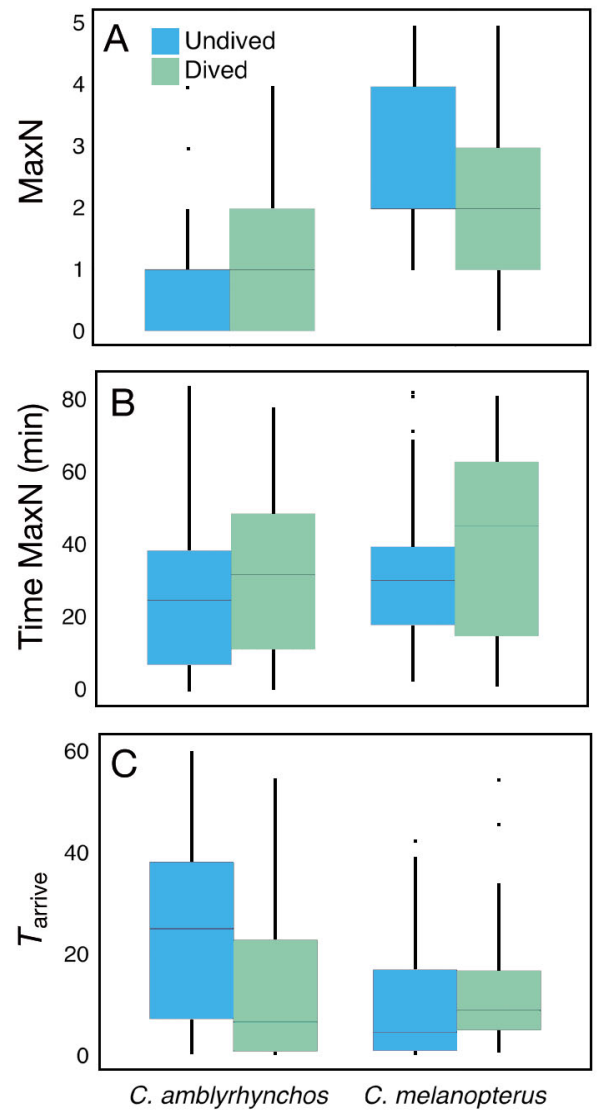

Fig. 3. (A) Relative abundance (MaxN), (B) time of MaxN, and $(\mathrm{C})$ time of arrival ( $\left.T_{\text {arrive }}\right)$ for blacktip reef sharks Carcharhinus melanopterus and grey reef sharks C. amblyrhynchos at dived and undived sites at Palmyra Atoll. Solid horizontal lines are medians, upper and lower box limits are 25th (Q1) and 75th (Q3) percentiles, and error bars represent Q1 $[1.5 \times(\mathrm{Q} 3-\mathrm{Q} 1)]$ and $\mathrm{Q} 3+[1.5 \times(\mathrm{Q} 3-\mathrm{Q} 1)]$, respectively. Data points outside these values are plotted individually

were excluded from the analyses. A minimum of 1 and a maximum of 11 sharks were present at each site, each month and year. There were no differences in residency across any month within a year $(\mathrm{p}>0.05$ for all months), between months in a dived and an undived year $(p=0.61)$, or between dived and un-

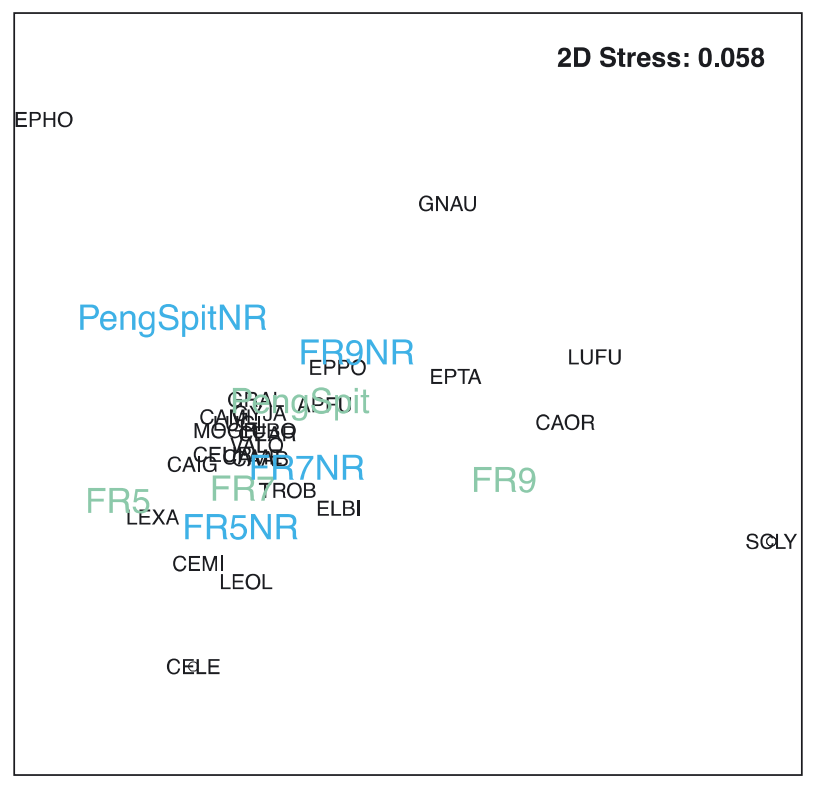

Fig. 4. Relative abundance non-metric multidimensional scale (nMDS) plot for overall predator faunal community assemblage in dived and undived sites at Palmyra Atoll. Dived sites (green): Penguin Spit (PengSpit), FR5, FR7, and FR9. Undived sites (blue): Penguin Spit non-research (PengSpit NR), FR5NR, FR7NR, and FR9NR. Black letters: species codes (for full species list see Table S1 in the Supplement at www.int-res.com/articles/suppl/m567p173_supp.pdf)

dived sites $(p=0.57)$ (Fig. 5A,C). The null model (random effects only) outperformed the model including effects for month, year, and dived and undived site (AIC $=201.1$ and 215.8, respectively). Sharks had significantly higher residency at only 1 site (Penguin Spit), which is a dived site, but this was consistent throughout both years (Fig. 5A,C). Residency at Penguin Spit ranged from 0.03 to 0.97 in 2014 with an average of 8 individuals present, and 0.03 to 0.39 in 2015 with an average of 3 individuals present.

Number of sharks present at dived and undived sites varied across months and between years, but patterns appeared biogeographical rather than dri- 

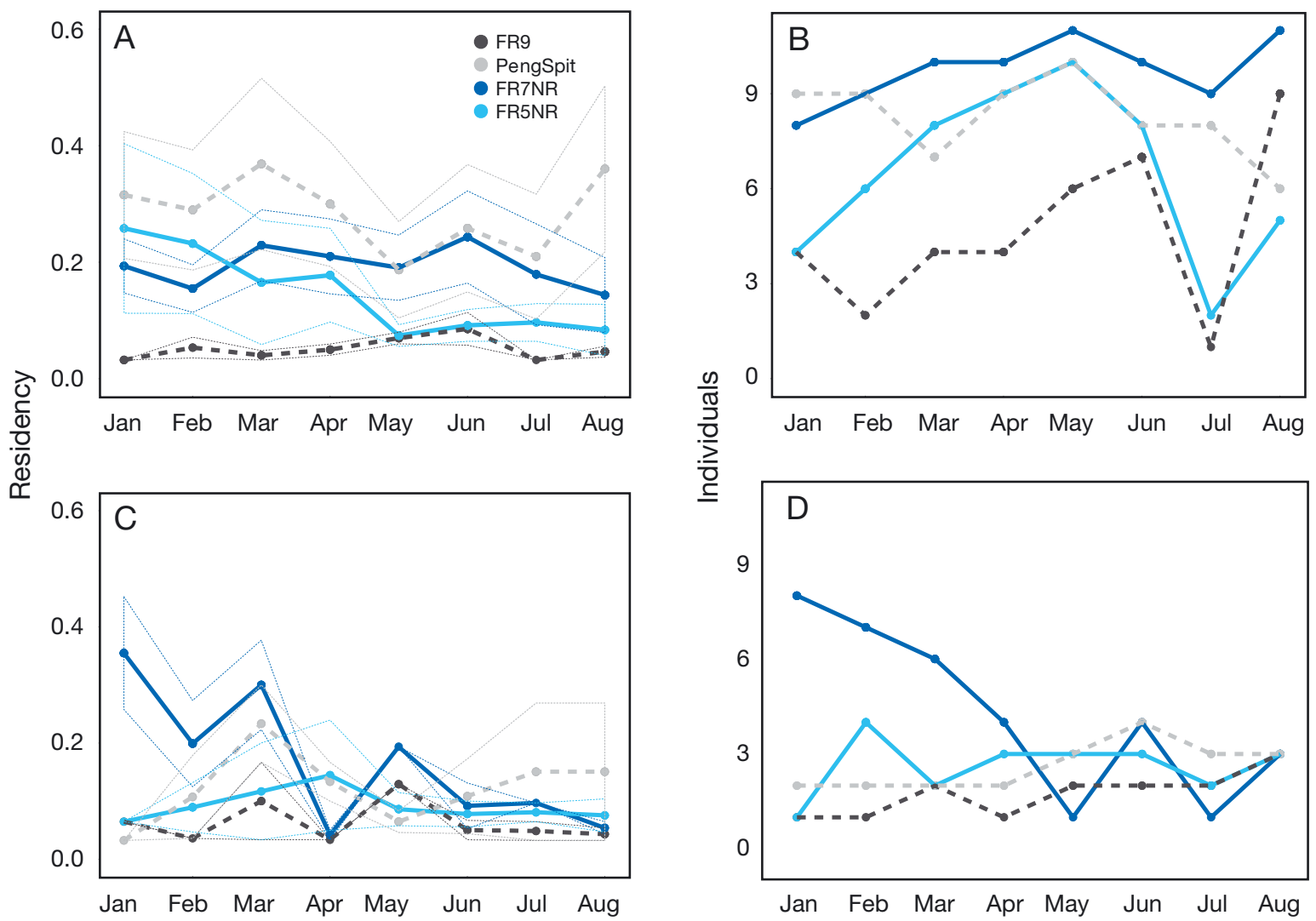

Fig. 5. Grey reef shark Carcharhinus amblyrhynchos residency (dotted lines: standard error) during January to August (A) 2014 and (C) 2015 at 2 dived (Penguin Spit and FR9) and 2 undived sites (FR7NR and FR5NR). Number of sharks present at each site each month in (B) 2014 and (D) 2015. Dashed lines: dived sites; solid lines: undived sites

ven by SCUBA diving activity. In 2014, number of sharks present peaked in May and decreased through August at southern dived and undived sites, while shark presence remained high throughout the year at the undived northern site (FR7NR) and was highly variable at the dived northern site (FR9) (Fig. 5B,D). Overall, fewer sharks were present at each site in 2015; however, with the exception of FR7NR, number of sharks present was relatively consistent throughout the year.

\section{DISCUSSION}

Our study did not support the hypothesis that persistent SCUBA diving activity results in permanent changes to reef shark behaviour and space use. While previous evidence has shown that sharks behaviourally respond to people in the water over immediate time scales (e.g. Smith et al. 2010, Cubero-Pardo et al. 2011, Baronio 2012), our results from a combination of survey techniques (BRUVs and passive acoustic monitoring) indicate that this response may not persist. The populations of sharks surrounding Palmyra have experienced nearly a decade of diving activity at a handful of sites where research has been conducted since 2001. Yet we found no evidence that sharks were actively avoiding (or were attracted to) those locations that experience persistent SCUBA diving in comparison to locations that are undived (Table 1). In other words, sharks did not alter their spatial distribution in response to persistent SCUBA diving. Likewise, following a year without any human diving activity at Palmyra, we did not detect differences in reef shark abundance or behaviour between heavily dived and undived locations (Table 1, Fig. 3), while controlling for their faunal communities (Fig. 4). There were also no differences in shark residency patterns at dived and undived sites in a year with substantial diving activity or between sites in years with and without SCUBA diving (Fig. 5). Ultimately, our findings suggest that SCUBA diving does not have long-term impacts on shark behaviour. This stands in stark contrast to the imme- 
diate effects of SCUBA diving on shark behaviour that have been reported elsewhere (e.g. Quiros 2007, Smith et al. 2010, Cubero-Pardo et al. 2011, Baronio 2012), but mirrors the findings from the shark feeding literature that showed provisioning also does not have long-term behavioural impacts on some shark species (Carcharodon carcharias, Carcharhinus perezii, Galeocerdo cuvier; Laroche et al. 2007, Maljkovi \& Côté 2011, Hammerschlag et al. 2012).

A possible explanation for our result is that sharks may have become habituated to the presence of SCUBA divers after $15 \mathrm{yr}$ of persistent exposure, which has been observed in other reef-dwelling species (Titus et al. 2015). If sharks were habituated to divers, then there would be no immediate behavioural response to SCUBA divers in the water, as well as no permanent change to shark behaviour and space use at dived locations. However, consistent with findings from other studies, there is evidence that reef sharks change their behaviour when confronted with SCUBA divers in the water at Palmyra. Different underwater diver-based survey methods revealed opposing trends in shark abundance on Palmyra's forereefs between 2002 and 2008 (NOAA Coral Reef Ecosystem Program, Pacific Island Fisheries Science Center [unpublished datasets] Ecosystem Monitoring \& Assessment: Rapid Ecological Assessments of Fish Belt Transect Survey [https:// inport.nmfs.noaa.gov/inport/item/5565, accessed September 16, 2015 (requirement to register)] \& Toweddiver Surveys of Large-bodied Fishes of U.S. Pacific Reefs since 2000 [https://inport.nmfs.noaa.gov/inport/ item/5568, accessed September 16, 2015]). Despite evidence that Palmyra's grey reef shark population is stable and may be at carrying capacity (Bradley et al. 2017), grey reef shark abundance appeared to be declining according to belt transect surveys, and increasing based on information from surveys conducted by towed SCUBA divers (Fig. S6 in the Supplement at www.int-res.com/articles/suppl/m567 p173_supp.pdf). These conflicting results indicate that sharks may have modified their immediate behavioural response to different types of diving activity in the water, and highlight the disadvantage of using SCUBA diver counts to estimate shark populations (Ward-Paige et al. 2010a). Crucially, however, by considering longer time scales and impacts of persistent diving activity, our results suggest that the immediate impacts by divers on shark behaviour described in other studies (e.g. Quiros 2007, Smith et al. 2010, Cubero-Pardo et al. 2011, Baronio 2012) may not persist or translate to long-term effects. Unlike terrestrial and marine mammals, which alter space use away from recreational activity (e.g. Constantine \& Zealand 2001, George \& Crooks 2006), we found no evidence of permanent spatial displacement in reef sharks in locations with persistent SCUBA diving. Ultimately, behavioural responses to SCUBA divers are likely context-dependent and may correlate with patterns of human use in complex ways (e.g. habituation to divers at regularly dived areas versus investigation of divers by naïve sharks; Ayling \& Choat 2008).

The economic benefits of shark diving tourism can significantly outperform shark exploitation (Anderson \& Ahmed 1993, Gallagher \& Hammerschlag 2011, Vianna et al. 2012, Cisneros-Montemayor et al. 2013), but realizing these benefits over long time scales requires minimizing negative ecological impacts to shark populations (Topelko \& Dearden 2005). At the same time, overly restrictive regulations can hinder potential economic gains from tourism activities. It is therefore critically important to understand not only how SCUBA divers immediately impact shark behaviour with their presence in the water, but also whether or not these immediate impacts have lasting effects that could undermine the economic value of shark tourism. In other words, will sharks that evade approaching SCUBA divers (e.g. Cubero-Pardo et al. 2011) permanently avoid SCUBA diving locations? Our results indicate that the answer to this question is 'not necessarily'; acute responses by sharks to the presence of SCUBA divers that have been observed elsewhere may not result in chronic changes to the spatial distribution of reef sharks. While Palmyra is unique in that it allows us to isolate SCUBA diving impacts on a marine system without fishing and recreational provisioning, it should be noted that diving impacts on Palmyra are lower than heavily dived tourist destinations, where individual sites may see thousands of SCUBA divers each year. Certainly, more intense diving, yearround diving, and/or unregulated diving in terms of species interaction guidelines could elicit stronger, potentially persistent behavioural responses by reef sharks to SCUBA divers. However, the diving pressure on Palmyra's dived sites did not affect the spatial distribution of sharks, which has implications for the spatial management of sharks and other mobile predators. In particular, our results indicate that temporary or seasonal closures of dive sites that reduce diving pressure to levels present at Palmyra could prevent the immediate behavioural impacts of divers on sharks from becoming permanent. We suggest that well-managed shark diving industries extend best-practice tourism regulations from in-water 
codes of conduct (e.g. no touching), to regulations that limit use of locations that experience persistent diving. Spatial management strategies that reduce or temporarily restrict diving and other recreational activities have been similarly suggested as a means to lessen the negative effects of recreation, including damage to coral cover and coral disease, which can effectively fortify sites against climatic stressors such as hurricanes (Hawkins \& Roberts 1992, Leujak \& Ormond 2008, Lamb et al. 2014). With a management structure in place that considers both immediate and long-term impacts of SCUBA diving on mobile predators, tourist operators can likely capture the economic benefits of tourism without experiencing strong negative environmental consequences.

Although persistent SCUBA diving activity may not permanently spatially displace reef sharks, the inherent mobility of sharks and other marine predators has been shown to independently undermine the efficacy of marine reserves designed to protect them from fishing (Chapman et al. 2005, McCook et al. 2010, Espinoza et al. 2014). Roughly $40 \%$ of coral reef marine protected areas (MPAs) are less than $2 \mathrm{~km}^{2}$ (Mora et al. 2006), far smaller than the activity spaces of many sharks and other vagile predatory reef fishes, which are often key fisheries' targets. Therefore, over short time scales, even moderate space use changes by sharks, such as temporary avoidance of divers (e.g. Quiros 2007, Cubero-Pardo et al. 2011, Baronio 2012), could be enough to cause a shark to leave a core habitat located within a small MPA. It is also important to note that relatively small behavioural changes in terms of space use might have been undetectable with our methods; both the detection range of a VR2 and the attraction radius of the bait plume over our 90 min BRUV surveys could potentially detect and attract sharks from 100 s of meters away. The value of sharks in shark diving tourism depends on tourists actually seeing them, and even small-scale movements away from divers could therefore have significant economic, as well as ecological, repercussions. However, our results indicate that humans can interact with reef sharks without persistent behavioural impacts, and that well-regulated shark diving tourism can likely be accomplished without undermining conservation goals.

Acknowledgements. We thank The Nature Conservancy staff for support at the Palmyra Atoll research station, K. Davis and P. Carlson for field assistance, L. Hornsby and W. Sedgwick for lab work, and A. Friedlander, C. Lowe, and K. Weng for the setup and maintenance of Palmyra's acoustic array; we also thank Steve Gaines, Bruce Kendall, Bob Warner, and April Ridlon for comments on an earlier version of this manuscript. Funding was provided by Save Our Seas Foundation (D.B.) and a Marisla Foundation grant (J.E.C.). D.B. was supported by a NSF Graduate Research Fellowship (DGE-114408) and an AAUS Kathy Johnston English Scholarship. This is publication number [PARC-0132] from the Palmyra Atoll Research Consortium (PARC). This research was conducted under US Fish and Wildlife permits \#1253314011 (2014) and \#12533-15011 (2015), and methods were carried out in accordance with relevant guidelines and regulations stated in our Institutional Animal Care and Use Committee (IACUC), University of California, Santa Barbara, Protocol no. 856 (date of IACUC approval: 5/31/2012).

\section{LITERATURE CITED}

Anderson R, Ahmed H (1993) The shark fisheries of the Maldives. MOFA Malé, FAO, Rome

Ayling AM, Choat JH (2008) Abundance patterns of reef sharks and predatory fishes on differently zoned reefs in the offshore Townsville region: final report to the Great Barrier Reef Marine Park Authority. Research Publication No. 91, Great Barrier Reef Marine Park Authority, Townsville

Babcock RC, Shears NT, Alcala AC, Barrett NS and others (2010) Decadal trends in marine reserves reveal differential rates of change in direct and indirect effects. Proc Natl Acad Sci USA 107:18256-18261

* Barnett A, Payne NL, Semmens JM, Fitzpatrick R (2016) Ecotourism increases the field metabolic rate of whitetip reef sharks. Biol Conserv 199:132-136

Baronio M (2012) The use of a micro remotely operated vehicle as a tool for studies of shark behaviour and diver impact. $\mathrm{PhD}$ thesis, Southern Cross University, Lismore

Bates D, Maechler M, Bolker B, Walker S (2015) Fitting linear mixed-effects models using lme4. J Stat Softw 67: $1-48$

Baum JK, Myers RA (2004) Shifting baselines and the decline of pelagic sharks in the Gulf of Mexico. Ecol Lett $7: 135-145$

* Biggs D, Ban NC, Hall CM (2012) Lifestyle values, resilience, and nature-based tourism's contribution to conservation on Australia's Great Barrier Reef. Environ Conserv 39:370-379

* Birt MJ, Harvey ES, Langlois TJ (2012) Within and between day variability in temperate reef fish assemblages: learned response to baited video. J Exp Mar Biol Ecol 416-417:92-100

Boo E (1991) Ecotourism: potentials and pitfalls. Prof Geogr 43:536-537

Boyle SA, Samson FB (1985) Effects of nonconsumptive recreation on wildlife: a review. Wildl Soc Bull 13: 110-116

Bradley D, Conklin E, Papastamatiou YP, McCauley DJ and others (2017) Resetting predator baselines in coral reef ecosystems. Sci Rep 7:43131

Brunnschweiler JM, Baensch H (2011) Seasonal and longterm changes in relative abundance of bull sharks from a tourist shark feeding site in Fiji. PLOS ONE 6:e16597

*B Brunnschweiler JM, Abrantes KG, Barnett A (2014) Longterm changes in species composition and relative abundances of sharks at a provisioning site. PLOS ONE 9: e86682

Cappo M, Speare P, De'ath G (2004) Comparison of baited remote underwater video stations (BRUVS) and prawn 
(shrimp) trawls for assessments of fish biodiversity in inter-reefal areas of the Great Barrier Reef Marine Park. J Exp Mar Biol Ecol 302:123-152

Cappo M, De G, Speare P (2007) Inter-reef vertebrate communities of the Great Barrier Reef Marine Park determined by baited remote underwater video stations. Mar Ecol Prog Ser 350:209-221

* Carlson JK, Heupel MR, Bethea DM, Hollensead LD (2008) Coastal habitat use and residency of juvenile Atlantic sharpnose sharks (Rhizoprionodon terraenovae). Estuaries Coasts 31:931-940

Chapman DD, Pikitch EK, Babcock E, Shivji MS (2005) Marine reserve design and evaluation using automated acoustic telemetry: a case-study involving coral reefassociated sharks in the Mesoamerican Caribbean. Mar Technol Soc J 39:42-55

* Cisneros-Montemayor AM, Barnes-Mauthe M, Al-Abdulrazzak D, Navarro-Holm E, Sumaila UR (2013) Global economic value of shark ecotourism: implications for conservation. Oryx 47:381-388

Ciuti S, Northrup JM, Muhly TB, Simi S, Musiani M, Pitt JA, Boyce MS (2012) Effects of humans on behaviour of wildlife exceed those of natural predators in a landscape of fear. PLOS ONE 7:e50611

Clua E, Buray N, Legendre P, Mourier J, Planes S (2010) Behavioural response of sicklefin lemon sharks Negaprion acutidens to underwater feeding for ecotourism purposes. Mar Ecol Prog Ser 414:257-266

Constantine R, Zealand N (2001) Increased avoidance of swimmers by wild bottlenose dolphins (Tursiops truncatus) due to long-term exposure to swim-with-dolphin tourism. Mar Mamm Sci 17:689-702

Constantine R, Brunton DH, Dennis T (2004) Dolphinwatching tour boats change bottlenose dolphin (Tursiops truncatus) behaviour. Biol Conserv 117:299-307

Cortés E, Neer JA (2006) Preliminary reassessment of the validity of the $5 \%$ fin to carcass weight ratio for sharks. Col Vol Sci Pap ICCAT 59:1025-1036

Cubero-Pardo P, Herrón P, González-Pérez F (2011) Shark reactions to scuba divers in two marine protected areas of the Eastern Tropical Pacific. Aquat Conserv 21: 239-246

Daves NK, Nammack MF (1998) US and international mechanisms for protecting and managing shark resources. Fish Res 39:223-228

Davidson LNK, Krawchuk MA, Dulvy NK (2015) Why have global shark and ray landings declined: improved management or overfishing? Fish Fish 17:438-458

Dobson J (2006) Sharks, wildlife tourism, and state regulation. Tour Mar Environ 3:15-23

* Ellenberg U, Mattern T, Seddon PJ, Jorquera GL (2006) Physiological and reproductive consequences of human disturbance in Humboldt penguins: the need for speciesspecific visitor management. Biol Conserv 133:95-106

Ellis DM, Demartini EE (1995) Evaluation of a video camera technique for indexing abundances of juvenile pink snapper Pristipomoides filamentosus, and other Hawaiian insular shelf fishes. Fish Bull 93:67-77

Espinoza M, Heupel MR, Tobin AJ, Simpfendorfer CA (2014) Residency patterns and movements of grey reef sharks (Carcharhinus amblyrhynchos) in semi-isolated coral reef habitats. Mar Biol 162:343-358

Ferretti F, Myers RA, Serena F, Lotze HK (2008) Loss of large predatory sharks from the Mediterranean Sea. Conserv Biol 22:952-964
Fitzpatrick R, Abrantes KG, Seymour J, Barnett A (2011) Variation in depth of whitetip reef sharks: Does provisioning ecotourism change their behaviour? Coral Reefs 30:569-577

*Gallagher AJ, Hammerschlag N (2011) Global shark currency: the distribution, frequency, and economic value of shark ecotourism. Curr Issues Tour 14:797-812

George SL, Crooks KR (2006) Recreation and large mammal activity in an urban nature reserve. Biol Conserv 133: 107-117

*Halpern BS, Longo C, Hardy D, McLeod KL and others (2012) An index to assess the health and benefits of the global ocean. Nature 488:615-620

*Hammerschlag N, Gallagher AJ, Wester J, Luo J, Ault JS (2012) Don't bite the hand that feeds: assessing ecological impacts of provisioning ecotourism on an apex marine predator. Funct Ecol 26:567-576

Harvey E, Shortis M, Robson S, Stadler M, Cappo M (1996) A system for stereo-video measurement of sub-tidal organisms: implications for assessments of reef fish stocks. Mar Technol Soc J 29:10-22

Harvey E, Fletcher D, Shortis M (2001) A comparison of the precision and accuracy of estimates of reef-fish lengths determined visually by divers with estimates produced by a stereo-video system. Fish Bull 99:63-71

Hawkins JP, Roberts CM (1992) Effects of recreational SCUBA diving on fore-reef slope communities of coral reefs. Biol Conserv 62:171-178

Hayes CT, Baumbach DS, Juma D, Dunbar SG (2016) Impacts of recreational diving on hawksbill sea turtle (Eretmochelys imbricata) behaviour in a marine protected area. J Sustain Tour 9582:1-17

*Heithaus MR, Frid A, Wirsing AJ, Worm B (2008) Predicting ecological consequences of marine top predator declines. Trends Ecol Evol 23:202-210

Kovacs KM, Innes S (1990) The impact of tourism on harp seals (Phoca groenlandica) in the Gulf of St. Lawrence, Canada. Appl Anim Behav Sci 26:15-26

Krüger O (2005) The role of ecotourism in conservation: Panacea or Pandora's box? Biodivers Conserv 14:579-600

Lamb JB, True JD, Piromvaragorn S, Willis BL (2014) Scuba diving damage and intensity of tourist activities increases coral disease prevalence. Biol Conserv 178:88-96

Laroche RK, Kock AA, Dill LM, Oosthuizen WH (2007) Effects of provisioning ecotourism activity on the behaviour of white sharks Carcharodon carcharias. Mar Ecol Prog Ser 338:199-209

* Leujak W, Ormond RFG (2008) Quantifying acceptable levels of visitor use on Red Sea reef flats. Aquat Conserv 18:930-944

Leung YF, Marion JL (2000) Recreation impacts and management in wilderness: a state-of-knowledge review. In: Cole DN, McCool SF, Borrie WT, O'Loughlin J (eds) Wilderness science in a time of change conference, Vol 5: wilderness ecosystems, threats and management. USDA Forest Service Proceedings RMRS-P-15-VOL-5, 23-27 May 1999, Missoula, MT. US Department of Agriculture, Forest Service, Rocky Mountain Research Station, Ogden, UT, p 23-48

Lusseau D (2004) The hidden cost of tourism: detecting longterm effects of tourism using behavioral information. Ecol Soc 9:2

Kadin EMP, Dill LM, Ridlon AD, Heithaus MR, Warner RR (2016) Human activities change marine ecosystems by altering predation risk. Glob Change Biol 22:44-60 
Malcolm H, Gladstone W, Lindfield S, Wraith J, Lynch T (2007) Spatial and temporal variation in reef fish assemblages of marine parks in New South Wales, Australia baited video observations. Mar Ecol Prog Ser 350:277-290

Maljkovi A, Côté IM (2011) Effects of tourism-related provisioning on the trophic signatures and movement patterns of an apex predator, the Caribbean reef shark. Biol Conserv 144:859-865

McCook LJ, Ayling T, Cappo M, Choat JH and others (2010) Adaptive management of the Great Barrier Reef: a globally significant demonstration of the benefits of networks of marine reserves. Proc Natl Acad Sci USA 107: 18278-18285

Meekan M, Cappo M (2004) Non-destructive techniques for rapid assessment of shark abundance in Northern Australia. Australian Institute of Marine Science, Townsville

Meyer CG, Dale JJ, Papastamatiou YP, Whitney NM, Holland KN (2009) Seasonal cycles and long-term trends in abundance and species composition of sharks associated with cage diving ecotourism activities in Hawaii. Environ Conserv 36:104-111

Mora C, Andrèfouët S, Costello MJ, Kranenburg C and others (2006) Coral reefs and the global network of Marine Protected Areas. Science 312:1750-1751

Müllner A, Eduard Linsenmair K, Wikelski M (2004) Exposure to ecotourism reduces survival and affects stress response in hoatzin chicks (Opisthocomus hoazin). Biol Conserv 118:549-558

Naylor LM, Wisdom MJ, Anthony RG (2009) Behavioral responses of North American elk to recreational activity. J Wildl Manag 73:328-338

Papastamatiou YP (2008) Movement patterns, foraging ecology, and digestive physiology of blacktip reef sharks, Carcharinus melanopterus, at Palmyra Atoll: a predator dominated ecosystem. PhD thesis, University of Hawaii, Manoa

*Papastamatiou YP, Lowe CG, Caselle JE, Friedlander AM (2009) Scale-dependent effects of habitat on movements and path structure of reef sharks at a predator-dominated atoll. Ecology 90:996-1008

Quiros AL (2007) Tourist compliance to a code of conduct and the resulting effects on whale shark (Rhincodon typus) behavior in Donsol, Philippines. Fish Res 84: 102-108

Robbins WD, Hisano M, Connolly SR, Choat JH (2006) Ongoing collapse of coral-reef shark populations. Curr Biol 16:2314-2319

Scarpaci C, Bigger SW, Corkeron PJ, Nugegoda D (2000) Bottlenose dolphins (Tursiops truncatus) increase whistling in the presence of 'swim-with-dolphin' tour operations. J Cetacean Res Manag 2:183-185

Semeniuk CAD, Rothley KD (2008) Costs of group-living for a normally solitary forager: effects of provisioning tourism on southern stingrays Dasyatis americana. Mar Ecol Prog Ser 357:271-282

Editorial responsibility: Scott Shaffer, San Jose, California, USA
Shackley M (1998) 'Stingray city': managing the impact of underwater tourism in the Cayman Islands. J Sustain Tour 6:328-338

Smith K, Scarr M, Scarpaci C (2010) Grey nurse shark (Carcharias taurus) diving tourism: tourist compliance and shark behaviour at Fish Rock, Australia. Environ Manage 46:699-710

Stafford-Bell R, Scarr M, Scarpaci C (2012) Behavioural responses of the Australian fur seal (Arctocephalus pusillus doriferus) to vessel traffic and presence of swimmers in Port Phillip Bay, Victoria, Australia. Aquat Mamm 38: 241-249

* Steven R, Pickering C, Guy Castley J (2011) A review of the impacts of nature based recreation on birds. J Environ Manage 92:2287-2294

* Sybersma S (2015) Review of shark legislation in Canada as a conservation tool. Mar Policy 61:121-126

* Titus BM, Daly M, Exton DA (2015) Do reef fish habituate to diver presence? Evidence from two reef sites with contrasting historical levels of SCUBA intensity in the Bay Islands, Honduras. PLOS ONE 10:e0119645

* Topelko KN, Dearden P (2005) The shark watching industry and its potential contribution to shark conservation. J Ecotour 4:108-128

V Vermeulen E, Cammareri A, Holsbeek L (2012) Alteration of southern right whale (Eubalaena australis) behaviour by human-induced disturbance in Bahía San Antonio, Patagonia, Argentina. Aquat Mamm 38:56-64

Vianna GMS, Meekan MG, Pannell DJ, Marsh SP, Meeuwig JJ (2012) Socio-economic value and community benefits from shark-diving tourism in Palau: a sustainable use of reef shark populations. Biol Conserv 145:267-277

*Ward-Paige C, Mills Flemming J, Lotze HK (2010a) Overestimating fish counts by non-instantaneous visual censuses: consequences for population and community descriptions. PLOS ONE 5:e11722

*Ward-Paige CA, Mora C, Lotze HK, Pattengill-Semmens C, McClenachan L, Arias-Castro E, Myers RA (2010b) Large-scale absence of sharks on reefs in the greater Caribbean: a footprint of human pressures. PLOS ONE 5: e11968

Whitmarsh SK, Fairweather PG, Huveneers C (2016) What is big BRUVver up to? Methods and uses of baited underwater video. Rev Fish Biol Fish, doi:10.1007/s11160-0169450-1

พWilliams R, Lusseau D, Hammond PS (2006) Estimating relative energetic costs of human disturbance to killer whales (Orcinus orca). Biol Conserv 133:301-311

* Willis T, Babcock R (2000) A baited underwater video system for the determination of relative density of carnivorous reef fish. Mar Freshw Res 51:755-763

พYasué M (2005) The effects of human presence, flock size and prey density on shorebird foraging rates. J Ethol 23: 199-204

Submitted: November 14, 2016; Accepted: January 9, 2017 Proofs received from author(s): February 27, 2017 